\title{
A novel technique for inferior rectus recession
}

This article was published in the following Dove Press journal:

Clinical Ophthalmology

21 January 2014

Number of times this article has been viewed

\section{Birsen Gokyigit \\ Serpil Akar \\ Omer Faruk Yilmaz}

Department of Strabismus, Istanbul Beyoglu Educational and Research Eye Hospital, Istanbul, Turkey
Correspondence: Birsen Gokyigit Tekfen Sitesi, Yagmur Apt D5, Ulus 34340, Istanbul, Turkey Tel :+90-532-246 3799 Fax:+90-2|2-613 5| 62 Email bgokyigit@hotmail.com; bgokyigit@dr.com
Purpose: To introduce a novel technique of inferior rectus recession operation to allow larger amounts of recession without causing lower lid retraction and to compare this method with the results obtained in standard inferior rectus recession.

Material and methods: This study included 20 patients operated on in the authors' clinic. The median age of the patients was $24.5 \pm 18.6(4-73)$ years and the median follow-up was $9.3 \pm 11.8$ (3-43) months. Ten patients operated on with the standard method were labeled Group 1 and ten patients operated on with the new method were labeled Group 2. Without exceeding $4 \mathrm{~mm}$, inferior rectus recession to the whole muscle was performed in Group 1 patients. Inferior rectus recession was also performed on patients in Group 2 following the new method. Using a spatula, approximately $10 \%$ of the muscle surface fibers were detached intact as a thin layer, and the remaining $90 \%$ of deeper fibers were recessed $4-8 \mathrm{~mm}$ as planned. Patients' preoperative deviations and lower lid positions were recorded. The same parameters were checked in the first and third month postoperatively. Both groups were evaluated retrospectively by screening their files, and the Mann-Whitney $U$ test was used for statistical evaluation.

Results: Lower lid retraction was seen in four patients of Group 1. There was no retraction in Group 2. While there was a need to perform additional vertical muscle procedures for vertical deviations and lower lid retractions in Group 1, it was observed that there was no need for additional procedures in Group 2 patients. There was a statistically meaningful difference between the two procedures $(P<0.05)$.

Conclusion: This novel technique was found to be an effective surgical method for permitting more recession without the risk of lower lid retraction.

Keywords: inferior rectus recession, lower lid retraction, ophthalmologic surgical procedures

\section{Introduction}

Lower lid retraction is a frequent undesirable result following inferior rectus recession operations. ${ }^{1-3}$ Especially in relatively larger amounts of recession, a special and close relationship between lower lid retractors and muscular fascia makes the complication more severe. Several techniques have been introduced to avoid lower lid retraction. One of these techniques, introduced in 1992, involves the posterior dissection of the muscle's fascia attachments and advancing the palpebral head forward. ${ }^{4,5}$ In 1996, to avoid lower lid retraction, Meyer et al introduced a different approach and defined the lysis of these retractors during surgery. ${ }^{6}$ It has been reported in several papers that both techniques and different versions have been successfully used..$^{7-10}$

The authors have created a novel approach, which was used successfully in their clinical study, for solving the lower lid retraction problem following inferior rectus 
recession in vertical strabismus without significant changes to the anatomical structure. The purpose of this study was to introduce a new technique and compare this method with the results obtained in standard inferior rectus recession.

\section{Material and methods}

This study included 20 patients who were examined, operated on, and followed up in the authors' Department of Strabismus, Istanbul Beyoglu Educational and Research Eye Hospital (Istanbul, Turkey). The new operation technique was created, and all operations were performed by the same surgeon (BG).

Approval from the Prof Dr N Reşat Belger Beyoglu Education and Research Eye Hospital Institutional Review Board and Ethics Committee was obtained. Affirmation of informed consent was obtained from each participant or one or both of the parents for patients younger than 18 years of age. The study and data collection conformed to all local laws and were compliant with the principles of the Declaration of Helsinki.

The patients who were operated on with the standard method were labeled Group 1 and those operated on with the new method were labeled Group 2. Each group included ten patients.
Demographic characteristics, diagnosis, applied operations, and follow-up time of Group 1 are shown in Table 1. The same characteristics for Group 2 are shown in Table 2.

In addition to a systematic full eye examination, suitable strabismus examination, which included motor and sensorial examination, was done in all patients. For motor evaluation, patients' deviations were measured in the nine cardinal positions of gaze with an alternate prism cover test performed for both near and distance. Krimsky and Hirschberg corneal reflex tests were performed for primary position. Bilateral fundus photographs and double Maddox examination were used for patients' torsion evaluation. For sensorial examination, Bagolini striated lenses, double Maddox tests for near, and Worth four-dot test for both near and distant evaluation were used. Sinoptophore examination was done both for horizontal, vertical, and torsional deviation measurement and for sensorial status evaluation, and Lees screen test was used in cooperating patients to show restriction. Primary position deviation values were taken into account for surgical treatment.

Standardized preoperative and postoperative photographs were taken to evaluate patients' lower lid positions. Local or general anesthesia was applied to patients. Topical anesthesia was not applied to any of the patients.

Table I Demographic characteristics, diagnosis, operations applied, preoperative and postoperative deviation values, amount of inferior rectus recession applied, preoperative and postoperative margin-to-reflex distance values, preoperative and postoperative vertical restrictions, and follow-up time of Group I

\begin{tabular}{|c|c|c|c|c|c|c|c|c|c|c|c|c|c|c|c|}
\hline 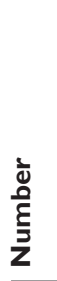 & 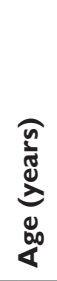 & ڤึ & 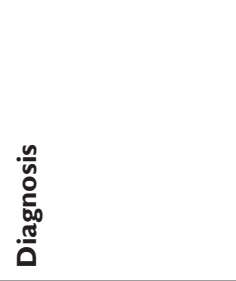 & 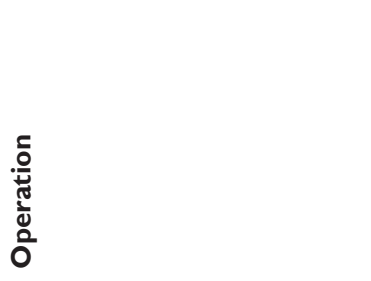 & 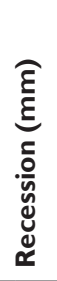 & 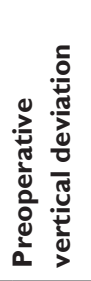 & 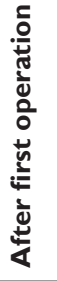 & 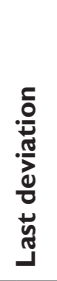 & 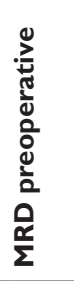 & 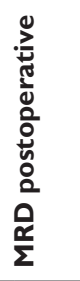 & 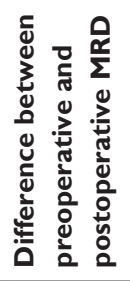 & 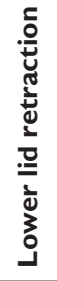 & 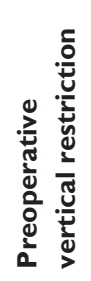 & 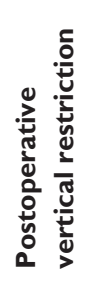 & 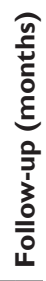 \\
\hline 1 & 5 & M & Left exo/hyper & $\begin{array}{l}\text { Right } L R \text { recession }+ \\
\text { IR recession + left SR resection }\end{array}$ & 4 & 20 & 12 & 0 & 5.02 & 5.04 & 0.02 & - & - & - & 3 \\
\hline 2 & 37 & M & $\begin{array}{l}\text { Left fourth cranial } \\
\text { nerve palsy }\end{array}$ & $\begin{array}{l}\text { Right MR recession + } \\
\text { IR recession }\end{array}$ & 5 & 40 & 30 & 10 & 5.11 & 6.16 & 1.05 & $3+$ & - & - & 43 \\
\hline 3 & 73 & $\mathrm{~F}$ & Strabismus fixus & $\begin{array}{l}\text { Bimedial recession + left IR } \\
\text { recession }\end{array}$ & 4 & 30 & 20 & 4 & 5.07 & 5.51 & 0.44 & + & -4 & -2 & 6 \\
\hline 4 & 26 & M & $\begin{array}{l}\text { Left adhesive } \\
\text { syndrome }\end{array}$ & $\begin{array}{l}\text { Right SR recession + left IR } \\
\text { recession }\end{array}$ & 4 & 30 & 20 & 6 & 5.22 & 5.36 & 0.16 & \pm & -4 & -2 & 4 \\
\hline 5 & 27 & $\mathrm{~F}$ & Left blowout & $\begin{array}{l}\text { Right } L R \text { recession + } \\
\text { IR recession }\end{array}$ & 3.5 & 18 & 8 & 0 & 5.11 & 7.01 & 1.90 & $4+$ & -4 & -3 & 9 \\
\hline 6 & 57 & $\mathrm{~F}$ & Left MED & Left Knapp + IR recession & 4 & 20 & 12 & 8 & 5.00 & 5.16 & 0.16 & \pm & -3 & -1 & 15 \\
\hline 7 & 9 & $M$ & Left hypotropia & Left IR recession & 4 & 50 & 45 & 30 & 5.14 & 5.16 & 0.02 & - & -1 & - & 12 \\
\hline 8 & 22 & $\mathrm{~F}$ & Right heavy eye & Right IR recession & 5 & 14 & 4 & 4 & 5.18 & 6.18 & 1.00 & $2+$ & -3 & -1 & 21 \\
\hline 9 & 37 & $M$ & Right ET + MED & Right IR recession & 4 & 25 & 14 & 10 & 5.30 & 5.33 & 0.03 & - & -3 & -1 & 8 \\
\hline 10 & 27 & $\mathrm{~F}$ & Left heavy eye & Left IR recession & 4 & 12 & 0 & 0 & 5.07 & 7.12 & 2.05 & $4+$ & -1 & - & 8 \\
\hline
\end{tabular}

Note: $\pm=$ lower lid retraction noticeable but less then $0.5 \mathrm{~mm}$.

Abbreviations: ET, esotropia; F, female; IR, inferior rectus; LR, lateral rectus; M, male; MED, monocular elevation deficiency; MRD, margin-to-reflex distance; SR, superior rectus; exo/hyper, exohypertropia. 
Table 2 Demographic characteristics, diagnosis, operations applied, preoperative and postoperative deviation values, amount of inferior rectus recession applied, preoperative and postoperative margin-to-reflex distance values, preoperative and postoperative vertical restrictions, and follow-up time of Group 2

\begin{tabular}{|c|c|c|c|c|c|c|c|c|c|c|c|c|c|c|}
\hline 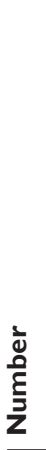 & 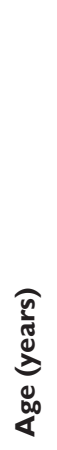 & ڤึ & 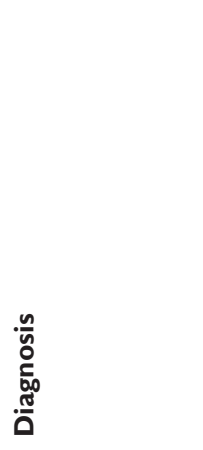 & 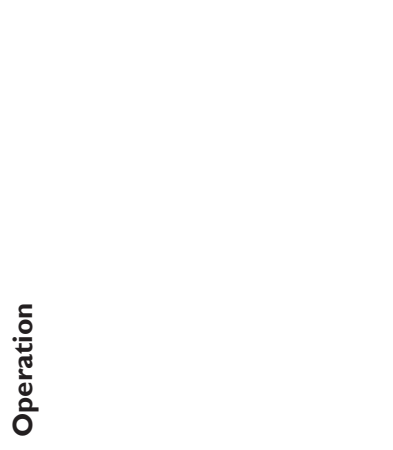 & 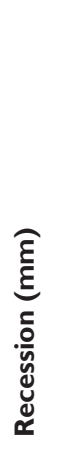 & 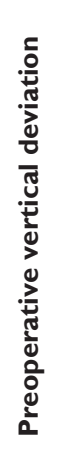 & 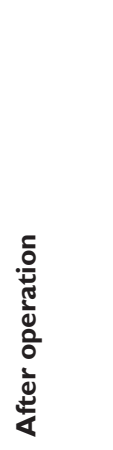 & 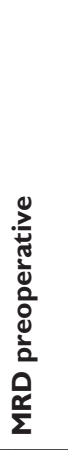 & 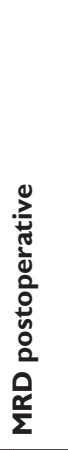 & 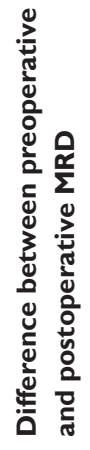 & 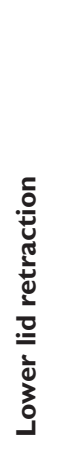 & 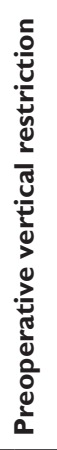 & 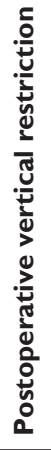 & 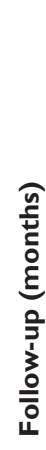 \\
\hline I & II & $M$ & Nystagmus & Bilateral IR recession & 5 & 0 & 0 & 5.08 & 5.10 & 0.02 & - & - & - & 5 \\
\hline 2 & 4 & $\mathrm{~F}$ & Right eso/hypo & Right IR recession & 4 & 25 & 4 & 5.12 & 5.14 & 0.02 & - & - & - & 7 \\
\hline 3 & 32 & $\mathrm{~F}$ & $\begin{array}{l}\mathrm{ET}+\mathrm{DVD}+ \\
\text { nystagmus }\end{array}$ & $\begin{array}{l}\text { Right } L R \text { recession + bilateral IO } \\
\text { recession + left IR recession }\end{array}$ & 4 & 0 & 0 & 5.25 & 5.25 & 0.00 & - & - & - & 8 \\
\hline 4 & 37 & $\mathrm{~F}$ & Right exo/hyper & Left Knapp + IR recession & 3 & 10 & 0 & 5.14 & 5.15 & 0.01 & - & -2 & - & 6 \\
\hline 5 & 9 & $M$ & Left exo/hyper & Right Knapp + IR recession & 4 & 0 & -4 & 5.31 & 5.30 & -0.01 & - & -2 & - & 5 \\
\hline 6 & 10 & $M$ & Right exo/hyper & Left Knapp + IR recession & 5.5 & 30 & 8 & 5.16 & 5.19 & 0.03 & - & -3 & - & 7 \\
\hline 7 & 8 & $\mathrm{~F}$ & Right exo/hyper & Left Knapp + IR recession & 7.5 & 40 & 6 & 5.03 & 5.28 & 0.25 & \pm & -4 & -1 & 6 \\
\hline 8 & 19 & M & Left MED & Left Knapp + IR recession & 4 & 0 & 0 & 5.17 & 5.17 & 0.00 & - & -3 & -1 & 5 \\
\hline 9 & 7 & $M$ & Right blowout & Right IR recession & 6 & 40 & $25 / 4$ pp & 5.06 & 5.21 & 0.15 & - & -3 & -2 & 4 \\
\hline 10 & 34 & $\mathrm{~F}$ & Right MED & Right Knapp + IR recession & 4 & 10 & 0 & 5.19 & 5.19 & 0.00 & - & -3 & - & 4 \\
\hline
\end{tabular}

Note: $\pm=$ lower lid retraction noticeable but less then $0.5 \mathrm{~mm}$.

Abbreviations: DVD, dissociated vertical deviation; ET, esotropia; F, female; IO, inferior oblique; IR, inferior rectus; LR, lateral rectus; M, male; MED, monocular elevation deficiency; MRD, margin-to-reflex distance; PP, primary position; exo/hyper, exohypertropia; eso/hypo, esohypotropia.

In eight of the Group 1 patients, in order not to cause lower lid retraction, inferior rectus recession was applied to the whole muscle, being careful to not exceed $4 \mathrm{~mm}$ to minimize the amount of eyelid retraction. ${ }^{11}$ After the globe was fixed with a $5 / 0$ silk suture about $1 \mathrm{~mm}$ from the limbus at the 3 o'clock and 9 o'clock level and after preparing limbal conjunctiva incision, conjunctiva was dissected from the sclera up to the inferior rectus. The inferior rectus was cleaned from the connective tissue surrounding the inferior rectus muscle and opened $1.5-2 \mathrm{~mm}$ from both sides and held with a hook. Intermuscular fascia, the intermuscular membrane, and all fascial attachments between the inferior rectus muscle and Lockwood's ligament were dissected as far posterior as possible to the posterior septum with blunt dissection. Two single-armed 6/0 vicryl sutures were passed and locked to both sides of the muscle, and the muscle was separated from its insertion. The muscle was then recessed and reinserted on the sclera at $4 \mathrm{~mm}$ posterior to the original insertion. In two cases (Cases 2 and 8), the inferior rectus muscle was hung back $5 \mathrm{~mm}$ from its original insertion.

In Group 2 patients, the conjunctiva was opened in the same way as a limbal conjunctival incision. The conjunctiva was enlarged with blunt dissection from the sclera to the inferior rectus. To reach the inferior rectus, $1.5-2 \mathrm{~mm}$ holes from surrounding tissue from both sides were opened and the inferior rectus was held with a hook. After the muscle was held with a hook (Figure 1), intermuscular fascia was recessed about $6 \mathrm{~mm}$; these tissues were recessed only for passing sutures and had locking safety from connective tissue interruption. By opening a tunnel, about $10 \%$ of the

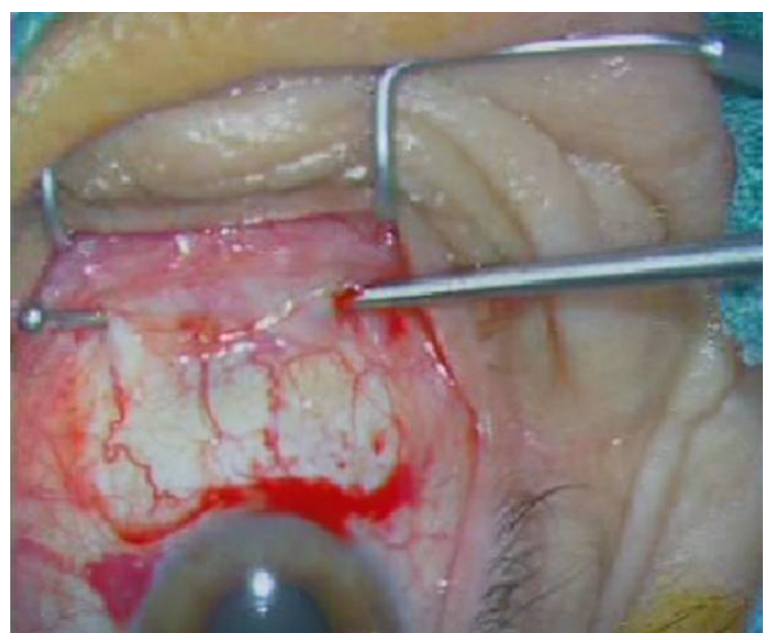

Figure I Muscle is held with a hook. 
muscle tendons' surface fibers, which surrounded the anterior ciliary arteries and all fascial attachments between the inferior rectus muscle and Lockwood's ligament, were detached from the remaining 90\% deeper fibers with fine capsule scissors (Figure 2). By putting a large thin iris spatula through this tunnel, the tunnel was enlarged 6-7 $\mathrm{mm}$ posteriorly with blunt dissection (Figure 3). Deeper parts of the tendon fibers were tied and fixed from both sides by a 6/0 vicryl suture and were dissected from insertion with scissors (Figure 4). After that, in order to separate surface and deeper parts of the fibers for enlargement posteriorly, the muscle was held with a clamp and stretched back as far as possible (Figure 5). The muscle, as planned, was fixed to the sclera $3-8 \mathrm{~mm}$ from the insertion with sutures on both sides (Figure 6). The conjunctiva was closed with $8 / 0$ vicryl sutures in both techniques.

An antibiotic and steroid drop combination was given to patients in both groups for a week.

Patients were examined on the first day, first week, and first month, and every 3 months periodically in the first year and annually in following periods. In these controls, all strabismus examinations done preoperatively were repeated. Their deviations were measured by the prism cover test. Standardized preoperative and postoperative photographs were taken. Lower lid retraction was determined by measuring the margin-to-reflex distance (MRD). The postoperative lower eyelid retraction was calculated by subtracting the preoperative MRD from the postoperative MRD. ${ }^{4,10}$ Each $0.5 \mathrm{~mm}$ difference between preoperative and postoperative measurements were evaluated as one (+).

The Mann-Whitney $U$ test was used for statistical evaluations.

\section{Results}

The median age of the patients was $24.5 \pm 18.6$ (4-73) years, and the median follow-up was $9.3 \pm 11.8(3-43)$ months.

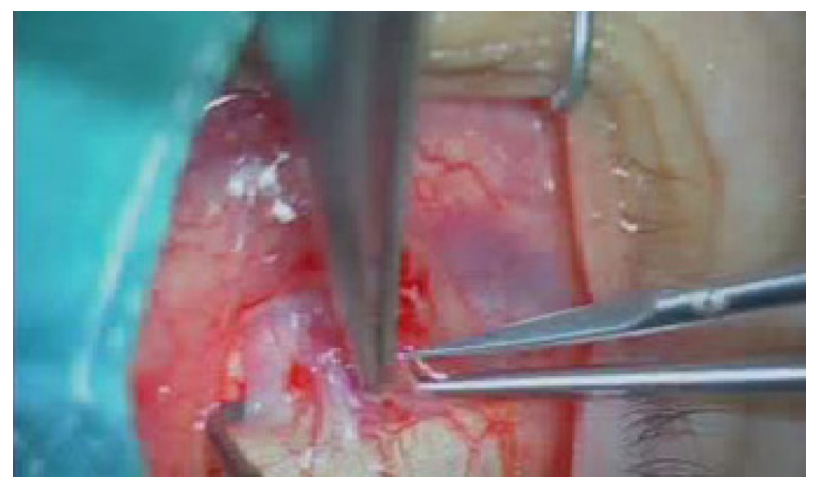

Figure 2 About 10\% of the muscle's surface fibers and related fascia were dissected from the remaining $90 \%$ deeper fibers with scissors.

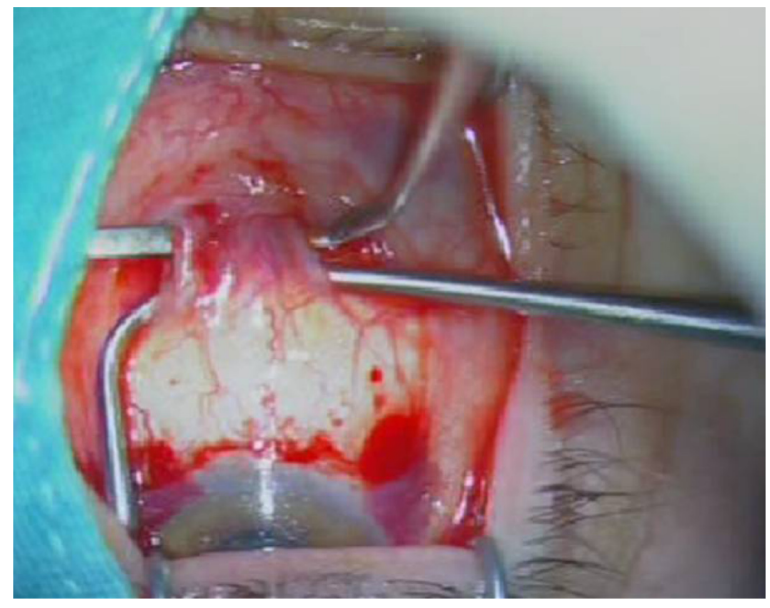

Figure 3 The tunnel was enlarged 6-7 mm posteriorly with blunt dissection.

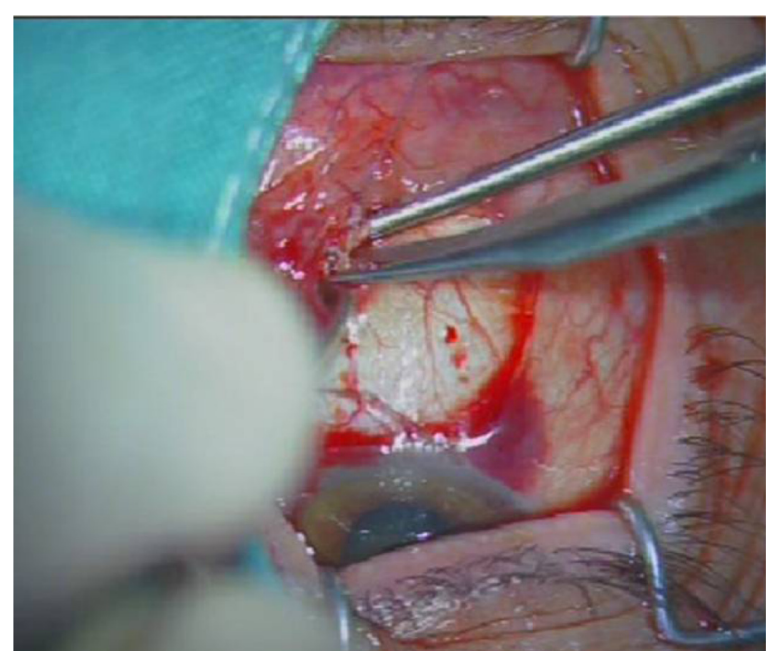

Figure 4 Scissors were used to separate the deeper fibers from the insertion after they were tied and fixed from both sides with a $6 / 0$ vicryl suture.

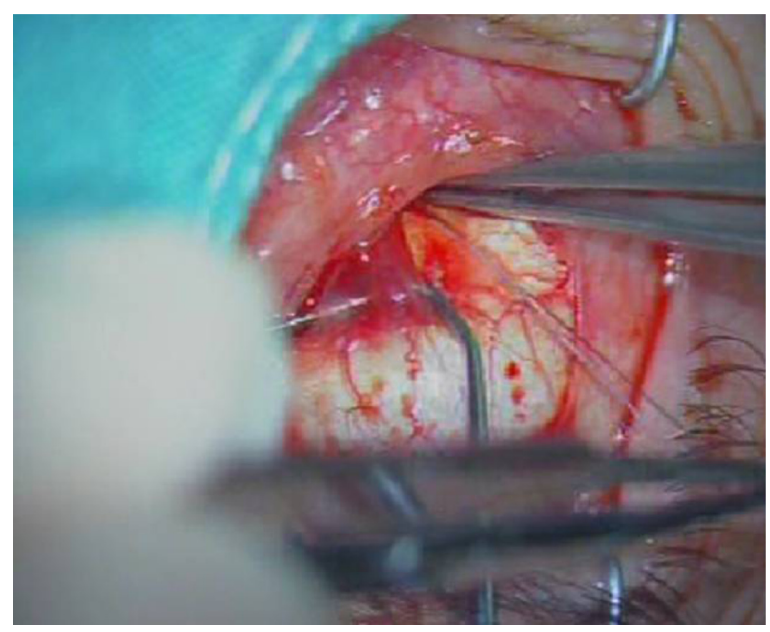

Figure 5 In order for the surface and deeper fibers to enlarge posteriorly, the muscle was held with a clamp and stretched back. During this procedure, when deeper fibers were stretched back, surface fibers and connective tissue were protected gently with large toothless forceps. 


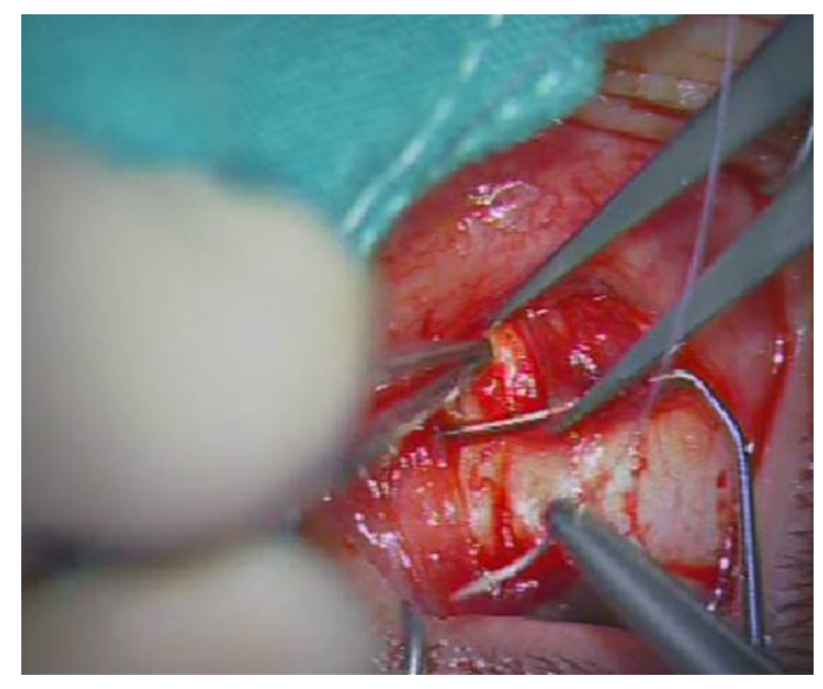

Figure 6 The muscle, as planned, was fixed to the sclera 3-6 $\mathrm{mm}$ from the insertion with sutures on both sides.

Lower lid retraction was seen in four Group 1 patients. There was no retraction in Group 2. While there was a need to perform second and third vertical muscle procedures for treating undercorrection for vertical deviations in Group 1, there was no need for additional vertical muscle procedures in Group 2 patients. When the groups were compared according to the number of surgeries, there was a statistically significant difference between the two procedures $(P<0.05)$.

Group 1 preoperative and postoperative deviation values, amount of inferior rectus recession performed, and the difference between preoperative and postoperative MRD values are shown in Table 1.

Except for three patients in Group 1 (Cases 2, 8, and 9), all patients needed a second or third operation in order to correct vertical deviation. Additional surgery was done for undercorrection. For one patient (Case 6) who did not need a second operation, horizontal muscle vertical transposition was performed. Increased recession with hang-back technique was performed for the other two patients (Cases 2 and 8).

Vertical correction in Group 1 patients was obtained but lower lid retraction in four patients (Cases 2, 5, 8, and 10) was unacceptable and additional reconstructive surgery was performed. Three patients (Cases 3, 4, and 6) had mild retraction and did not need any additional cosmetic surgery.

Oculoplastic surgery was not performed simultaneously. If it was needed, surgery was performed at least 3 months later after the strabismus surgery.

Preoperative and postoperative deviation values, amount of inferior rectus recession applied, and difference between preoperative and postoperative MRD of Group 2 are shown in Table 2.
In Group 2, vertical deviation was completely corrected in one session for all patients except two (Cases 2 and 9), and six of the patients (Cases 4, 5, 6, 7, 8, and 10) had additional vertical transposition of the horizontal muscles during the same session. There was no lower lid retraction in patients of this group except for an acceptable scleral show in one patient (Case 7).

There was no statistically significant difference in the preoperative MRDs of Group 1 and Group $2(P=0.186)$, but there was a statistically significant difference in the postoperative MRDs $(P<0.001)$.

As more muscle surgery was performed in one session in Group 2, the final results of Group 1 were taken into account when the motor success of Group 2 was evaluated.

Following the operation, the patients' sensorial status did not change.

\section{Discussion}

The inferior rectus muscle's special anatomical position being close to the inferior oblique and lower lid retractors and the intermuscular membranes and fascia - leads to an important complication of lower lid retraction following recession surgery of this muscle. Because of this complication, the classic knowledge mentioned in the textbooks is to not exceed more than $4 \mathrm{~mm}$ recess when performing lower rectus recession. When it is necessary to exceed this amount, it is advised that the vertical deviation be corrected by doing additional procedures in other vertical muscles. ${ }^{1}$

In order to avoid these complications, Helveston suggested a large dissection going up to the vortex veins. ${ }^{2}$ However, in this study, noticeable lid retraction was not able to be avoided with this classic method despite using large dissection in all cases.

In order to eliminate this complication, Jampolsky suggested suturing the capsulopalpebral head separately from the recessed inferior rectus. ${ }^{3}$ The capsulopalpebral head was advanced by Kushner following inferior rectus recession, who used this method and demonstrated that lower lid retraction can be avoided. ${ }^{4}$ Pacheco et al stated that the complication can be minimized by improving this technique with adjustable form. ${ }^{5}$ Following this application, many authors have stated that they have obtained successful results with this technique. ${ }^{7,8}$ However, this technique with adjustable form was used in a few of the current cases with no effective results for lower lid position. For this reason, the authors discontinued using this technique.

Meyer et $\mathrm{al}^{6}$ stated that the retractor lysis technique, explained by Holds et al, ${ }^{12}$ performed in the same session 
with inferior rectus recession has given very successful results in many different indications. An improved technique performed in the same clinic also minimized lower lid retraction. ${ }^{9}$ Likewise, this technique has been shown to be very effective, especially in restrictive cases. ${ }^{10}$ However, the authors do not have any experience with it.

The technique of recessing the $90 \%$ deeper fibers of the inferior rectus muscle while keeping the approximate 10\% surface fibers attached, as described in this study, avoids lower lid retraction in patients and protects normal anatomical structures with a high success rate.

There was one case in both Group 1 and Group 2 with muscle entrapment without interruption due to blowout fracture who also benefited from this particular technique.

It was observed that this technique necessitates the presence of normal or near-to-normal undisrupted anatomical structures in the inferior rectus muscle region for successful outcomes. The technique itself avoids trauma to the inferior rectus muscle and its neighboring ligaments because only the deeper part of the muscle with related connective tissue is operated upon. Since the surface muscle fibers and related connective tissue have been protected to avoid damage to the main structures, postoperative overcorrection due to muscle slippage can be prevented.

Another advantage of this technique is the preservation of the anterior ciliary arteries. Therefore, other recti muscle procedures can be performed in the same session without impeding anterior segment ischemia.

A weakness of the authors' technique is that it cannot be performed with success in patients with muscles that are severely adhered to the globe, in patients with swollen muscles due to deposition of glycosaminoglycans, in patients with fibrosis, in patients in late stages of dysthyroid ophthalmopathy, or in patients with severe traumatic restrictive deviations.

Due to the retrospective nature of the present study, there are some limitations. Patients in the two groups were not homogeneous according to their diagnosis and amount of vertical deviation. Because almost all patients in Group 1 were operated on before performing the new technique, their operations were performed with several steps to prevent anterior segment ischemia. However, in Group 2, planned operations were needed to be performed on multiple muscles in the same session. Of course, these differences changed the motor success, with a big improvement in Group 2 following the first operation. The effect of the new technique solely on the one muscle (inferior rectus) could not be compared to standard recession effects. However, the authors' aim was to introduce the new technique and its preventive effect of lower lid retraction. Of course, the small number of patients is another limitation to achieving statistically significant results. For evaluation of the real motor effects of this new technique, further study that includes patients with homogeneous diagnosis and vertical deviations is needed.

This technique requires the use of a microscope and some expertise in muscle surgery as the $10 \%$ surface fiber bundle can easily be disinserted with vigorous manipulation. Therefore, meticulous care in dissecting the two bundles is highly recommended.

\section{Conclusion}

The novel technique described in this study does not require additional lower lid procedures. In addition, complications that might be seen with the standard technique, eg, symblepharon, are avoided and the anatomical structure of the muscle and adnexal tissues is widely protected. It also has the advantage of protecting the anterior ciliary arteries during surgery. This new novel technique was found to be an effective surgical method that permitted more recession without the risk of lower lid retraction.

\section{Disclosure}

The authors report no conflicts of interest in this work. The authors are not supported or funded by any pharmaceutical company.

\section{References}

1. von Noorden GK, Campos EC. Binocular Vision and Ocular Motility: Theory and Management of Strabismus. 6th ed. St Louis, MO: Mosby; 2002.

2. Helveston EM. Pediatric ophthalmology and strabismus. In: Transactions of the New Orleans Academy of Ophthalmology. New York, NY: Raven Press Books; 1986:61-70.

3. Jampolsky A. Management of vertical strabismus. In: Transactions of the New Orleans Academy of Ophthalmology. New York, NY: Raven Press Books; 1986:141-171.

4. Kushner BJ. A surgical procedure to minimize lower-eyelid retraction with inferior rectus recession. Arch Ophthalmol. 1992;110(7):1011-1014.

5. Pacheco EM, Guyton DL, Repka MX. Changes in eyelid position accompanying vertical rectus muscle surgery and prevention of lower lid retraction with adjustable surgery. J Pediatr Ophthalmol Strabismus. 1992;29(5):265-272.

6. Meyer DR, Simon JW, Kansora M. Primary infratarsal lower eyelid retractor lysis to prevent eyelid retraction after inferior rectus muscle recession. Am J Ophthalmol. 1996;122(3):331-339.

7. Scotcher SM, O'Flynn EA, Morris RJ. Inferior rectus recession - an effective procedure? Br J Ophthalmol. 1997;81(12):1031-1036.

8. Kose S, Uretmen O, Emre S, Pamukcu K. Recession of the inferior rectus muscle under topical anesthesia in thyroid ophthalmopathy. $J$ Pediatr Ophthalmol Strabismus. 2002;39(6):331-335. 
9. Kim DB, Meyer DR, Simon JW. Retractor lysis as prophylaxis for lower lid retraction following inferior rectus recession. J Pediatr Ophthalmol Strabismus. 2002;39(4):198-202.

10. Liao SL, Shih MJ, Lin LL. A procedure to minimize lower lid retraction during large inferior rectus recession in Graves ophthalmopathy. Am J Ophthalmol. 2006;141(2):340-345.
11. Helveston EM. Surgical Management of Strabismus. 5th ed. Oostende: Wayenborgh Publishing; 2005.

12. Holds JB, Anderson RL, Thiese SM. Lower eyelid retraction: a minimal incision surgical approach to retractor lysis. Ophthalmic Surg. 1990; 21(11):767-771
Clinical Ophthalmology

\section{Publish your work in this journal}

Clinical Ophthalmology is an international, peer-reviewed journal covering all subspecialties within ophthalmology. Key topics include: Optometry; Visual science; Pharmacology and drug therapy in eye diseases; Basic Sciences; Primary and Secondary eye care; Patien Safety and Quality of Care Improvements. This journal is indexed on

Submit your manuscript here: http://www.dovepress.com/clinical-ophthalmology-journal

\section{Dovepress}

PubMed Central and CAS, and is the official journal of The Society of Clinical Ophthalmology (SCO). The manuscript management system is completely online and includes a very quick and fair peer-review system, which is all easy to use. Visit http://www.dovepress.com/ testimonials.php to read real quotes from published authors. 